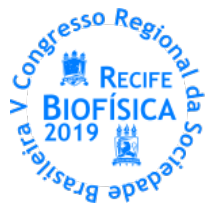

\title{
A2CN NA MODULAÇÃO DE BKCa E SUA INFLUÊNCIA NAS CARACTERÍSTICAS INVASIVAS DE CÉLULAS TUMORAIS
}

\author{
Lucas E.L. Terceiro ${ }^{1 *}$, Aliny P. Vasconcelos ${ }^{1}$, Jader S. Cruz², Mário L.A.A. Vasconcellos ${ }^{1}$, Demetrius A. M. Araújo \\ ${ }^{1}$ Laboratório de Biotecnologia Celular e Molecular, UFPB; ${ }^{2}$ UFMG. \\ *lucaselt.sk@outlook.com
}

\section{RESUMO}

Introdução: Apesar dos avanços e desenvolvimento da ciência e tecnologia na área da saúde, a incidência e mortalidade por câncer continuam aumentando, consistindo em um dos maiores problemas de saúde pública. Sendo assim, os Adutos de Morita-Baylis-Hillman vêm ganhando destaque nas pesquisas farmacológicas por apresentarem diversos efeitos biológicos promissores no tratamento do câncer. Dessa forma, o presente estudo teve como objetivo avaliar o efeito do $\mathrm{AMBH}$ : $\mathrm{A} 2 \mathrm{CN}$ em células de câncer de mama triplo-negativo (4T1), nas respostas relacionadas a invasão celular. Além de verificar se os efeitos estariam relacionados com a modulação de canais de potássio ativados por cálcio de grande condutância (BKCa). Metodologia: Foram realizados experimentos para determinação da $\mathrm{Cl}_{50}$ na linhagem 4T1 através do método de redução de MTT. Posteriormente, foram realizados ensaios de proliferação, migração, adesão e invasão celular para observar os efeitos celulares modulados pelo composto. Além disso, foi realizado registros eletrofisiológicos de correntes de potássio do tipo BKCa. Para isso, foi utilizada a técnica de patch-clamp no modo whole cell, em que após estabilidade do selo $(>1 \mathrm{G} \Omega)$ foram disparados pulsos despolarizantes de $-60 \mathrm{mV}$ a $+80 \mathrm{mV}$, com 15 segundos de intervalo. Resultados: Os resultados mostraram que, o composto após $72 \mathrm{~h}$ de tratamento apresentou $\mathrm{Cl}_{50}$ igual a 28,8 \pm $2,3 \mu \mathrm{M}$, em $24 \mathrm{~h}$ o $\mathrm{Cl}_{50}>200 \mu \mathrm{M}$, apresentando efeito dose e tempo dependentes. A taxa de proliferação celular foi reduzida sendo que concentrações de $25,12,5$ e $6,25 \mu \mathrm{M}$ o composto reduziu a proliferação em $98,7,74,9$ e $44,5 \%$ comparado ao controle não tratado. Na migração celular, o A2CN nas concentrações de 12,5 e $50 \mu \mathrm{M}$ apresentou efeito inibitório no fechamento da ferida, após 16 h. Nos ensaios de adesão celular, $\mathrm{A} 2 \mathrm{CN}$ à $50 \mu \mathrm{M}$, apresentou inibição da adesão de aproximadamente $25 \%$ e $20 \%$, nas matrizes de laminina e fibronectina, respectivamente. Além disso, concentrações crescentes de $\mathrm{A} 2 \mathrm{CN}$ demonstraram causar modificações morfológicas nas células. Utilizando um modelo tridimensional para avaliação de metástase in vitro, foi possível observar que o $\mathrm{A} 2 \mathrm{CN}$ reduziu o processo de invasão celular. Ocorreu uma inibição da área invadida pelas células nas concentrações de 12,5 , 25 e $50 \mu \mathrm{M}$ correspondente a 70,8\%, 93,2\% e $98,5 \%$, respectivamente. A amplitude de correntes de potássio foi medida na situação controle, bem como na presença de 100nM de Iberotoxina (IBX), $50 \mu \mathrm{M}$ de $\mathrm{A} 2 \mathrm{CN}$, e IBX mais $\mathrm{A} 2 \mathrm{CN}$. Na presença de IBX a amplitude de corrente de potássio (Ik) foi reduzida de 297,9 pA para 99,7 pA. Apresentando uma inibição de $61,27 \pm 2,49 \%$ caracterizando como componente majoritário do registro de corrente de potássio do tipo BKCa. Na presença de $50 \mu \mathrm{M}$ de $\mathrm{A} 2 \mathrm{CN}$ a inibição de corrente foi de $60,53 \pm 5,04 \%$ quando comparados com o controle. Para avaliar se a redução da lk na presença do $\mathrm{A} 2 \mathrm{CN}$ está sendo mediada por $\mathrm{BKca}$, foram obtidos registros de $\mathrm{lk}$ com incubação de IBX mais $\mathrm{A} 2 \mathrm{CN}$ e observou-se uma inibição de corrente de $67,6 \pm 4,96 \%$. Sendo assim, pode-se concluir que o $\mathrm{A} 2 \mathrm{CN}$ apresentou atividade anticâncer e foi capaz de atuar de forma inibitória em processos celulares responsáveis pela malignificação da doença. 